\title{
Integrating Technology in Qatar's Higher Education Settings: What Helps Faculty Accomplish the Job
}

\author{
Ibrahim M. Karkouti ${ }^{1}$ iD
}

Accepted: 2 July 2021 / Published online: 14 July 2021

(C) The Author(s), under exclusive licence to Springer Nature B.V. 2021

\begin{abstract}
This qualitative, exploratory case study elicited faculty members' perceptions of the factors that facilitate technology integration into their instruction. The sample for the study constituted 14 full-time male professors at a public midsized postsecondary institution in Qatar. Davis's technology acceptance model is the theoretical framework that guided this study and served as the theoretical lens through which data were collected and analyzed. Procedures associated with qualitative research were used to analyze the data collected from the interviews. Salient findings that emerged from this investigation, such as basic technology skills, digital content availability, career enhancement, and self-confidence were perceived as major requirements for successful technology integration practices. Cultural restrictions were also perceived to enhance the use of technology for instructional purposes. Recommendations for future research are provided in light of the derived findings.
\end{abstract}

Keywords Educational technology $\cdot$ Faculty behavior $\cdot$ Faculty development $\cdot$ Higher education $\cdot$ Instructional technology $\cdot$ Technology integration

\section{Introduction}

Current technological advancements are changing the world around us and in order to prepare students to be contributing members of society, education must reflect these advancements (Smith, 2009). Teacher accreditation organizations and professional associations have developed standards that recognize "that technology skills are contemporary expectations in all educational settings" (Javeri \& Persichette, 2007, p. 29). While technology is the goal, research on how it is effectively integrated into higher education classrooms remains uncharted (Keengwe, 2007; Porter et al., 2014), and even fewer studies have examined technology integration from an international perspective (Turugare \& Rudhumbu, 2020).

Technology integration is the term used in the literature to describe intentional classroom practices that utilize technology to support instruction, promote learning of content, and

Ibrahim M. Karkouti

ibrahim.karkouti@aucegypt.edu

1 Graduate School of Education, The American University in Cairo, AUC Avenue,

New Cairo 11835, Egypt 
demonstrate mastery of that content (Cradler et al., 2002; Koruyan, 2016; Okojie et al., 2006). Technology integration encompasses all types of technology-based instructional practices including, for example, information and communication technologies (ICT), e-learning, distance education, and online learning. While these terms are often used interchangeably in the literature, they each involve different levels and types of software, hardware, electronic information systems, and communication devices (Bhatia \& Mittal, 2009; Moore et al., 2011). For the purpose of this study, technology integration comprises "the incorporation of technology resources and technology-based practices into the daily routines, work, and management of schools" (National Center for Education Statistics [NCES], 2002, p. 75).

Universities worldwide have adopted computer-based technologies, such as multimedia classrooms, online learning formats, and social media Internet applications, in an attempt to enhance the quality of their educational programs (Tang \& Austin, 2009; U.S. Department of Education, 2017). Despite technology's being ever present, several factors appear to hinder effective integration of technology into instruction (Faudler, 2011; Surry et al., 2005). These factors include the absence of institutional and technical support, lack of time, and technophobia (Adams, 2002; Brown, 2016; Dempsey et al., 2008; Fathema et al., 2015; Kaminski $\&$ Bolliger, 2012). Researchers have also found that a lack of resources, training, and professional development negatively affect the technology integration process in the classroom (Ertmer, 2005; Leggett \& Persichitte, 1998; Martirosyan et al., 2017; Rogers, 2000a, 2000b).

Several studies on faculty professional development have found that technology workshops can improve faculty technology proficiency and increase the likelihood of technology integration by faculty (Adams, 2002; Brown, 2016; Dempsey et al., 2008; Fathema et al., 2015; Georgina \& Olson, 2007; Kaminski \& Bolliger, 2012; Vannatta \& Beyerbach, 2000). Notably, several authors have suggested that faculty members' behaviors and attitudes toward technology can markedly influence its incorporation into their instruction (Abouchedid \& Eid, 2004; Brill \& Galloway, 2007; Brown, 2016; Kim et al., 2013; Tabata \& Johnsrud, 2008; Wickersham \& McElhany, 2010). Research also indicates that institutional and technical support is essential if faculty members are to accept technological innovations and use them effectively in their classrooms (Brill \& Galloway, 2007; Fathema et al., 2015; Tabata \& Johnsrud, 2008; Wickersham \& McElhany, 2010).

In Qatar, local authorities have made substantial investments in educational technology resources. Nevertheless, teaching in Qatar remains outdated and teacher-centered, focusing on students' development of lower-order thinking skills (Nasser, 2017; Wiseman \& Anderson, 2012). While Qatar's higher education institutions have made sizeable investments to increase the availability of technological tools in the classroom (Weber, 2010), authors have suggested that various cultural and psychological factors appear to be hindering university faculty members' technology integration practices (Al-Jaber \& Dutta, 2008; Bahgat, 1999; Karkouti, 2016; Weber, 2010; Wiseman \& Anderson, 2012). Given the Qatari's government emphasis on being globally competitive and the concomitant need to have a technologically skilled workforce, a study that brings to light university faculty members' understanding of the factors that facilitate technology integration within their instructional practice seems both timely and important. 


\section{Significance of the Study}

This study adds to the existing body of literature related to technology integration within higher education in the Arab world, specifically Qatar. While studies have been conducted from various countries regarding technology integration (e.g., Abouchedid \& Eid, 2004; Adams, 2002; Al-Senaidi et al., 2009; Dempsey et al., 2008; Georgina \& Olson, 2007; Kaminski \& Bolliger, 2012; Leggett \& Persichitte, 1998; Safar \& Alkhezzi, 2013; Turugare \& Rudhumbu, 2020; Vannatta \& Beyerbach, 2000), research specifically aimed at technology integration in Qatar's institutions of higher education is considerably limited. This study addresses this gap in the knowledge base.

The majority of studies on technology integration in Qatar have used quantitative research methods. These studies only sampled K-12 teachers and postsecondary students, not university professors (e.g., Alkhateeb, 2019; Chaaban \& Ellili-Cherif, 2017). Few, if any, published peer-reviewed reports of empirical investigations on technology integration sought to gather postsecondary faculty perceptions of the factors that facilitate technology integration into their instruction using qualitative measures (Karkouti, 2016). This study addresses this methodological gap in the literature by employing qualitative interviews that explores faculty members' perceptions of the factors that facilitate technology integration into their instruction.

This study is also relevant in terms of the population being sampled. It is evident that the sociocultural background in Qatar differs significantly from that found in Western nations, such as the United States (Kamal \& Maruyama, 1990). This distinction creates a much different climate for the use of technology, and the literature indicates that the national mindset, religion, culture, and traditions strongly affect Qatar's educational system, control people's lives, and govern all aspects of Qatari society (Romanowski \& Nasser, 2012; Rostron, 2009). The use of technology is also influenced by sociopolitical norms, such as the political climate, stakeholders' resistance to change, lack of professional human capital, misconceptions about modern technology, and Internet censorship (Al-Jaber \& Dutta, 2008; Bahgat, 1999; Wiseman \& Anderson, 2012). Given the above considerations, this study becomes of primary importance because it gives voice to an understudied population in the Middle East, male university faculty members in Qatar, and allows their unique experiences to be heard.

\subsection{Literature Review}

Technology represents a powerful change agent that has transformed the world into a global society and currently permeates many aspects of nearly everyone's life (Adams, 2002; Keengwe, 2007; Schindler et al., 2017; Smith, 2009). Technology literacy, which encompasses "computer skills and the ability to use computers and other technology to improve learning, productivity, and performance" (U.S. Department of Education, 1996, p. 7) is considered a strong indicator of job readiness and an essential requirement of employability in the twenty-first century (Kaminski \& Bolliger, 2012). Technology literacy is also a major requirement for economic and social advancement because modern technologies are an essential part of today's business, industry, and education environments (Edwyn, 2001; Karkouti, 2016). Having workers who are adept with various technologies is imperative to their competitiveness in the global economy (Cheng et al., 2018). Today, the global workforce relies on technology systems to boost professional performance in the 
workplace, and technology illiteracy remains one of the main concerns of employers (Gay, 2019; Kaminski \& Bolliger, 2012).

Institutions of higher education have been "struggling to assume the leadership role demanded of them by society to produce technology-savvy citizens to participate at the highly skilled levels required to support [the] society's growing technological needs" (Adams, 2002, p. 285). As such, technology integration into higher education classrooms has become an educational imperative that must be implemented without excuses (Smith, 2009). Using technology, universities worldwide are expected to reform their educational system, develop curricula, enhance faculty technology literacy, and improve student learning (Kumpulainen, 2007; Smith, 2009; Tang \& Austin, 2009; Yilmaz et al., 2020). Modern technologies provide higher education institutions with new teaching and learning opportunities conducive to student success (Brill \& Galloway, 2007), and today's college students expect the presence of computer-based technologies in their classrooms (Hecht, 2001; Schindler et al., 2017). According to researchers, as students' expectations for a technologically rich educational experience increase, educators are encouraged by those expectations to integrate technology into their instruction (Sturgeon, 2011; Surry et al., 2005).

To provide their students with advanced educational experiences that prepare them to assume leading positions in the global knowledge society, faculty members are expected to use technology in their classrooms (McLoughlin et al., 2008), and evidence suggests that technology is changing the ways faculty members teach their courses (Anthony et al., 2020). While some faculty members willingly integrate technology into their instruction, others decide not to do so (Sturgeon, 2011; Yilmaz et al., 2020). The present study is aimed at uncovering the factors that promote technology integration in higher education classrooms in order to facilitate all faculty feeling competent and comfortable in seamlessly including technology integration in their curricular planning and instruction.

\subsection{Defining Technology Integration}

It is essential to explain the intricate relationship between technology integration, learning, and instruction. Technology integration is often narrowly perceived by educators and researchers who disregard the importance of aligning specific technological resources with course content, student learning outcomes, and methods of instruction (Okojie et al., 2006). Diaz and Bontenbal (2000) explain this point further:

Using technology to enhance the educational process involves more than just learning how to use a specific piece of hardware and software. It requires an understanding of pedagogical principles that are specific to the use of technology in an instructional setting. (p. 2)

In an attempt to correct this common misconception, Okojie et al. (2006) provide a detailed explanation of the term technology integration. First, technology integration should be treated as an integral component of teaching if faculty members are to facilitate learning and enhance students' academic achievement. Specifically, technology integration should be considered during lesson preparation when faculty members are "developing learning objectives, methods of instruction, feedback, and evaluation and assessment strategies including follow-up activities" (p. 66). Second, technology integration requires faculty members to mobilize and utilize technological resources, such as software applications, hardware, and electronic media at the classroom level during the process of instructional preparation and not as an afterthought activity. These techniques are beneficial for 
educators because they allow them to use appropriate technology resources based on the learning needs of their students as well as the objectives of their lesson. Third, technology, learning, and instruction should be viewed as a tripartite model that supports and facilitates students' academic success, and develops educators' critical thinking skills as they practice technology integration and "examine the appropriateness of the technologies they are using and whether such technologies are compatible with their lesson plan and learning outcomes" (p. 68). Finally, according to Okojie et al. (2006), technology integration is a major element of the instructional milieu that needs to be acknowledged by educators trying to implement technology in their classrooms. Failure to consider the strong association between technology integration, learning, and instruction will degrade the quality of education in a technology-based learning environment and lead to poor use of technology for instructional and learning purposes.

Similarly, the technological and pedagogical content knowledge framework (TPACK) posits that a complex array of factors are in play when teachers use technology for instructional purposes (Koehler \& Mishra, 2008), and all factors are required for successful integration. Scherer et al. (2021) relied on the TPACK framework in their international study to develop profiles of teacher readiness in higher education to take up online teaching in response to the COVID-19 pandemic. Using latent profile analysis, the study team identified low readiness, inconsistent readiness, and high readiness with culture and prior experience, among others factors, as determinants of profile membership. They noted that countries with long-term goals also were more likely to have higher education teachers who exhibited high readiness.

In line with the explanation above, technology integration is defined for the purposes of this study as the directed use of technological resources, such as hardware, software applications, communication devices, online learning platforms, and electronic media, in a classroom setting to support and promote instruction, enhance student learning, and improve the overall quality of education.

\subsection{Arab Nations and Technology Integration}

Technology integration in education is considered a powerful instructional tool that enhances students' academic achievement (Anderson \& Horn, 2012; Anthony et al., 2020; Safar \& Alkhezzi, 2013; Stanley, 2013; Tang \& Austin, 2009) and provides students with advanced educational experiences beyond the scope of traditional classrooms (Schindler et al., 2017; Wegner et al., 1999). To this point, many countries have developed educational policies that aim to create a skilled workforce ready to compete in a global economy by supporting the integration of technology into teaching and learning (United Nations Educational, Scientific \& Cultural Organization [UNESCO], 2013). Although technology literacy is an important issue for higher education institutions in the Arab world (Kindilchie \& Samarraie, 2008), and despite initiatives, such as the United Nations Development Program (UNDP, 2001), the implementation of technology into higher education in the Arab world still lags behind that of Western developed countries (Badran et al., 2019). For example, Arab countries still lack national policies that govern e-learning, recognize online degrees, or offer guidance on how to integrate technology into higher education classrooms (Abouchedid \& Eid, 2004; Faek, 2020; Mirza \& Al-Abdulkareem, 2011; Sadik, 2013; Safar \& Alkhezzi, 2013).

In an attempt to bridge the digital divide between the Arab world and technologically advanced nations, the Jordanian Ministry of Education pursued significant investment 
strategies to procure educational technology resources to enhance the country's educational system, improve faculty performance, and prepare a generation of skilled workers to participate in future knowledge-based economies (Abu Samak, 2010). The Jordanian case has been internationally recognized as a leading educational initiative that promotes the use of technology resources to enhance human capital, promote economic development, and reduce poverty (UNESCO, 2013).

In a similar context, in 2010, the Emir of Kuwait, his Highness Sheikh Sabah bin Ahmad Al Sabah, called for a national movement to reform the public education system. Although Kuwait's education reform initiative successfully provided all public schools and universities with advanced technological resources, little emphasis was placed on how to effectively integrate technology into curricula and instruction (Safar \& Alkhezzi, 2013). In the Sultanate of Oman, the Sultan Qaboos University started offering e-learning programs using WebCT, a learning management system, back in 2001 (Weber, 2010). Nevertheless, the use of technology for educational purposes remains underutilized in Omani higher education institutions because faculty members often resist the integration of technology into their instruction for several reasons, including fear of technology (technophobia), disbelief about technology's benefits, and absence of institutional and technical support (Al-Senaidi et al., 2009; Karkouti, 2016).

\subsection{Current Technology Issues in the State of Qatar}

In 2003, Qatar, the country in which this study was conducted, launched a major education reform that primarily focuses on establishing the country as a developed nation through the enhancement of its national human capital and by preparing Qatari citizens to sustain the development of their socioeconomic system (Brewer et al., 2007; Stasz et al., 2007). Qatar's educational reform sought to develop students' critical thinking skills through an advanced educational system that prepares a new generation of skilled professionals to establish their country as a fully-developed nation (Rostron, 2009; Stasz et al., 2007). A major goal is to prepare its citizens to survive in the international economy after the nation's oil and gas reserves have dwindled (Reilly, 2008). However, a dearth of technologically skilled workers in Qatar appears to be a major barrier to greater technology acceptance in the fields of education, health, and government (Al-Jaber \& Dutta, 2008; Karkouti, 2016).

Consistent with other Arab nations, in 2005, the Emir of Qatar, his Highness Sheikh Tamim bin Hamad Al Thani, launched a country-wide technological reform that aimed to "create an advanced information and communication technologies (ICT) community where the community at large can use ICT to improve the quality of their lives and actively contribute to the social and economic development of Qatar" (Al-Jaber \& Dutta, 2008, p. 133). Although Qatar's higher education institutions have made sizeable investments to increase the availability of technological tools in the classroom (Weber, 2010), the availability of technological resources has been insufficient in improving Qatar's educational system (Nasser, 2017; Wiseman \& Anderson, 2012). Furthermore, Qatar's university officials have often criticized students' technological skills claiming that graduates are incapable of using computers and other types of technologies (Brewer et al., 2007). The lack of technology skills is therefore the product of teacher-centered programs that focus on developing students' lower-order thinking skills (Nasser, 2017; Wiseman \& Anderson, 2012).

Straub et al. (1997) asserted that the technology integration process is directly affected by various economic, sociological, organizational, and psychological factors. For Qatar, 
and other Arab Gulf countries, the apparent dearth of technology integration in educational settings may be attributed in part to Internet censorship and limited Arabic content (Bahgat, 1999; Ibrahim et al., 2020; Karkouti, 2016; Kindilchie \& Samarraie, 2008). The limitations imposed by the cultural context of education in Qatar, such as stakeholders' resistance to change, misconceptions about technology, and social and religious norms may also obstruct the development of a technology-rich learning community (Al-Jaber \& Dutta, 2008; Karkouti, 2016). For example, Qatari citizens and foreign residents cannot access Internet websites that contradict Islamic values and national policies (Romanowski \& Nasser, 2012). Little is known, however, about the impact of these factors on Qatari institutions of the higher education.

\subsection{Theoretical Framework}

Davis's (1986) technology acceptance model (TAM) guided the data collection and analysis for this study. This model was designed specifically to explain an individual's behavior related to the use of any computer-based technology or system (Davis et al., 1989). TAM is an adaptation of Fishbein and Ajzen's (1975) theory of reasoned action (TRA) in which the authors posited that individuals' behaviors emanate from their intentions, which are in turn based on a combination of their attitudes toward the behavior and their perceptions of how others want them to perform the behavior (norms). Davis (1986) replaced TRA's norms construct with two technology acceptance constructs: perceived usefulness and perceived ease of use. Davis $(1986,1989)$ argued that perceived usefulness and perceived ease of use are the only two beliefs that can predict a person's attitudes toward technology acceptance and usage. Davis (1986) applied TRA as a theoretical lens to explore the relationships between two major concepts: (a) the perceived usefulness and ease of use of technology and (b) a person's attitudes, behavioral intentions, and actual technology acceptance behaviors.

TAM (Davis, 1986) encompasses four interrelated constructs: (a) external variables, (b) perceived usefulness of the technology, (c) perceived ease of using the technology, and (d) attitude toward using the technology. The model holds that these four constructs combine to form a person's intention to use any computer-based technology or system, and intentions are predictive of whether a person will do so. The model suggests two factors directly affect technology acceptance and usage (Davis, 1989). First, the implementation of an application depends on the extent to which people perceive it as helpful in doing a better job (perceived usefulness; Davis, 1989). Second, even if people perceive an application is useful, they may, at the same time, "believe that the system is too difficult to use so that the benefit of usage is outweighed by the effort involved in implementing the application" (perceived ease of use; Davis, 1989, p. 320).

Several researchers have validated the utility of TAM as an effective framework for explaining technology acceptance and usage behaviors (Davis, 1989; Davis et al., 1989; Li et al., 2019; Shams Eldin, 2020). Others have extended TAM by taking one of three approaches: (a) introducing factors from relevant frameworks (Taylor \& Todd, 1995), (b) examining external variables that are considered as antecedents and moderators of perceived usefulness and perceived ease of use (Venkatesh, 2000), or (c) adding similar or alternative belief factors to the framework (Venkatesh \& Davis, 2000; Wixom \& Todd, 2005).

Results from research related to technology acceptance behaviors suggest that TAM is a suitable model for use in this study because it provides a framework through which 


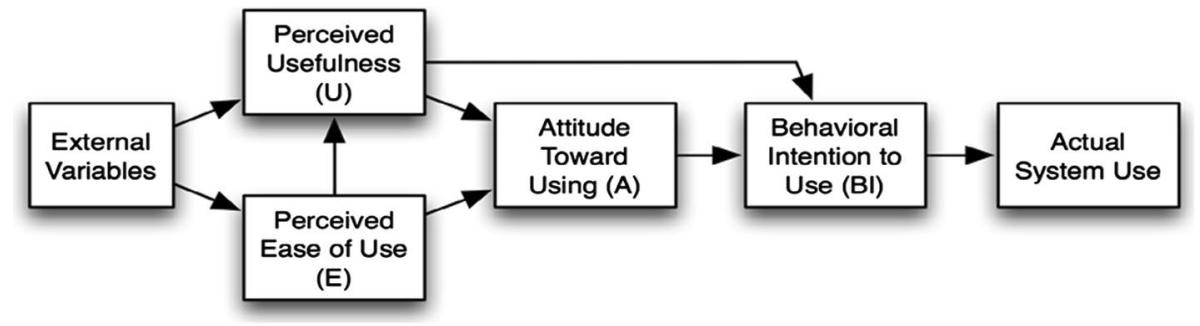

Fig. 1 Interaction among the components of TAM (Davis, 1986)

Table 1 Summary of Davis's (1986) Technology Acceptance Model

\begin{tabular}{|c|c|}
\hline Components & Description \\
\hline External Variables & $\begin{array}{l}\text { External variables are factors, such as demographic or personality characteristics } \\
\text { of the individual, the nature of the particular behavior under consideration, } \\
\text { motivation to comply, characteristics of referents, prior behavior, and persuasive } \\
\text { communication. In addition, external variables include all factors that are not } \\
\text { explicitly mentioned in the model (Davis, } 1986, \text { p. } 21 \text { ) }\end{array}$ \\
\hline Perceived Usefulness & $\begin{array}{l}\text { The extent to which a person perceives a particular system to be beneficial in terms } \\
\text { of professional development and performance enhancement }\end{array}$ \\
\hline Perceived Ease of Use & $\begin{array}{l}\text { The extent to which a person perceives a particular system to be user-friendly. } \\
\text { Perceived ease of use is hypothesized to have a significant effect on perceived } \\
\text { usefulness, because a system that is easier to use will result in increased job } \\
\text { performance for the user }\end{array}$ \\
\hline Attitude & $\begin{array}{l}\text { Identified by a person's feelings that could promote or prevent the application of a } \\
\text { particular system }\end{array}$ \\
\hline Behavioral Intention & The extent to which a person is willing to perform a specific behavior or task \\
\hline
\end{tabular}

the factors that may influence faculty members' use of technology in their instruction can be identified (Camilleri \& Camilleri, 2017; Hassad, 2013; Yuen \& Ma, 2002). Although researchers have used this framework to explain technology usage behaviors in technologically advanced nations (e.g., Anthony et al., 2020; Camilleri \& Camilleri, 2017; Casey et al., 2020), there are no studies that have implemented this model in Qatar. Thus, this investigation adds to the current understanding of the model and tests its utility in a new context. Figure 1 provides a graphic representation of how the model components interact to predict whether individuals will actually use technology in their work (Casas, 2010; Davis, 1986; Davis et al., 1989).

In this model, the external variables directly affect the perceived usefulness of technology and perceived ease of use (Davis, 1986; Shroff et al., 2011; Venkatesh \& Davis, 2000). Perceived usefulness is directly affected by perceived ease of use and these variables jointly determine an individual's attitude toward using particular technology within an organizational context (Davis, 1986, 1989). A person's attitude toward using particular technology and perceived usefulness of that technology influence the individual's behavioral intention to use the technology, and intentions are predictive of a person performing an action that is positively perceived (Davis et al., 1989). Table 1 provides a summary of the model components. 


\section{Research Questions}

The study was guided by four research questions that align with Davis's (1986) TAM. In order to identify the factors that facilitate technology integration into instruction, study participants answered the following research questions:

1. Which external factors do faculty members perceive as facilitating technology integration into their instruction?

2. What are faculty members' perceptions regarding the usefulness of technology integration in their instruction?

3. What are faculty members' perceptions regarding the ease of using technology in their instruction?

4. What factors influence faculty attitudes toward integrating technology into their instruction?

\section{Method}

An exploratory case study research design was selected to investigate faculty members' perceptions of the factors that facilitate technology integration into their instruction. Yin (2014) explained that exploratory case studies are used to explore those issues where the intervention being assessed has no clear single set of results. Not only do they explore a topic of interest, exploratory case studies precisely describe research settings, the problem being addressed, the methods of exploration, the findings of the study, and the implications for future research (Yin, 2014). Consistent with Yin, this case study explored a phenomenon in a real-world setting where the researcher clarified the importance of the investigation and explained how it helps faculty trying to integrate technology into their instruction.

\subsection{Nature of the Setting}

The research site is a midsized higher education institution in Qatar that provides over 10,000 students with more than 60 educational programs. The university is internationally recognized and an active member of the Union of Arab Universities, the League of Islamic Universities, and the International Association of Universities. In addition, all schools are internationally accredited from prestigious accrediting bodies in Canada, United Kingdom, and the United States. The student-faculty ratio is $14: 1$, and instructors are renowned scholars from different Arab and foreign countries who support the university's mission in developing its research and educational infrastructure.

The university emphasizes the use of technology in its mission statement and has equipped all of its classes with state of the art technology tools and software. Not only do they use Blackboard, students enjoy a wide range of equipment such as I-clickers, interactive whiteboards, podcasting tools, smart projectors, and mobile devices. Each semester, students evaluate faculty performance against multiple teaching criteria including technology use inside the classroom. 


\subsection{Sample Description}

Due to restrictions imposed by Qatar's social norms and because many non-Qatari residents avoid discussing sensitive topics such as Internet censorship, government policies, or cultural issues (Romanowski \& Nasser, 2012), establishing a culture of trust with potential participants was a challenging task. Therefore, the sample for the study was purposively selected using the snowball sampling technique. In effect, snowball sampling is a nonprobability sampling method in which the researcher "sample[s] a small group of participants relevant to the research questions, and these sampled participants propose other participants who have had the experience or characteristics relevant to the research" (Bryman, 2012, p. 424).

To overcome sampling difficulties, the researcher contacted three department chairs who referred him to 17 faculty members, three of whom were female professors. However, given the cultural practices in Qatar where public education is segregated by gender (Breslin \& Jones, 2010; Karkouti, 2016), the researcher, who is male, only interviewed 14 male professors because access to female campus buildings and offices was not granted. The researcher tried to communicate with female faculty via email; however, none expressed their interest in conducting interviews over the phone or via Zoom.

Since qualitative research has no specific rules for sample size (Patton, 2002), the sample for this investigation consisted of 14 male full-time assistant and associate professors. Specifically, the sample for this study was drawn from three colleges within a single university: College of Education $(n=8,57.14 \%)$, College of Engineering $(n=3$, $21.42 \%)$, and College of Arts and Sciences $(n=3,21.42 \%)$. All participants taught multiple courses for graduate and undergraduate students. To maintain their confidentiality, each of the interviewees is identified using a pseudonym. Table 2 contains demographic information about the sample.

\subsection{Data Collection Procedures}

Qualitative researchers have a wide variety of research tools that can be used to collect important data from individuals or groups (Bryman, 2012). The semi-structured interview is the research tool that was used in this study. In person, semi-structured interviews were conducted in either Arabic or English, depending on the interviewee's preference. The researcher, who is bilingual, met with the participants to explain the study procedures and obtain their consent.

The interviews occurred in the university auditorium and lasted approximately 45 to $60 \mathrm{~min}$ at a time that was mutually agreed upon. The researcher audio-recorded all interviews and made handwritten notes to track valuable insights using interview notes templates. To ensure a clear understanding of the investigated phenomenon, the researcher asked probing questions and employed active listening techniques, such as rephrasing and paraphrasing interview questions.

\subsection{Data Analysis}

Verbatim interview transcripts served as the data set for analysis. In order to reduce the volume of information and gain more insight of the explored issue, data collected from audio-recorders and field notes were manually transcribed and coded. Text analysis was 


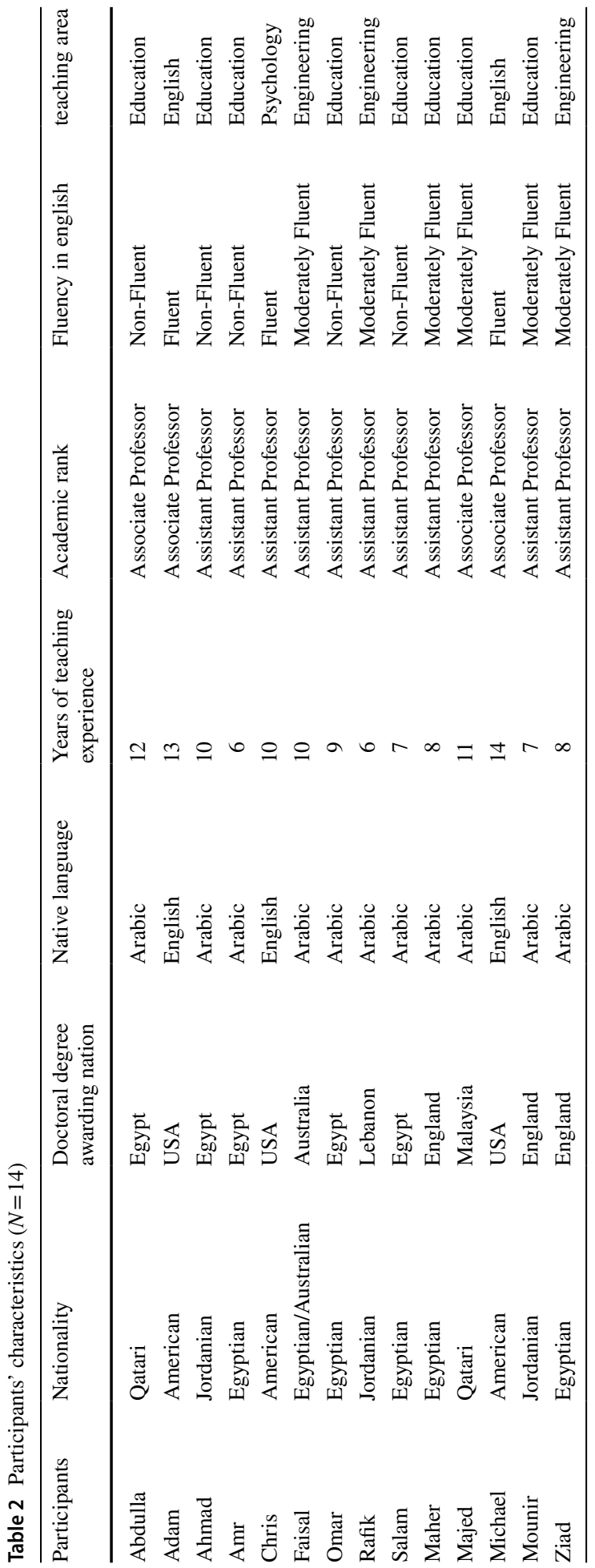


performed using the transcribed data and data displays in the form of matrices that were developed using the coded materials. This procedure allowed the researcher to breakdown, sort, organize, and categorize major themes and findings derived from interview data (Strauss \& Corbin, 1990).

Data coding was guided by the research questions and TAM's constructs. Open coding allowed the researcher to explore in-depth ideas contained in the data, which in turn facilitated the process of interrelating and interpreting the meaning of the derived themes (Jones et al., 2014). The derived themes were content analyzed, refined, and checked for redundancy before presenting them as direct quotes from the participants.

Finally, to ensure validity and reliability, the researcher carefully reported the process through which data were gathered and analyzed, double-checked transcripts to avoid common mistakes, and adhered to study protocols in order to allow future replication. Further, all participants were asked to review their interview transcript in order to enhance the accuracy of their responses. Figure 2 summarizes the data analysis and validation processes in the study.

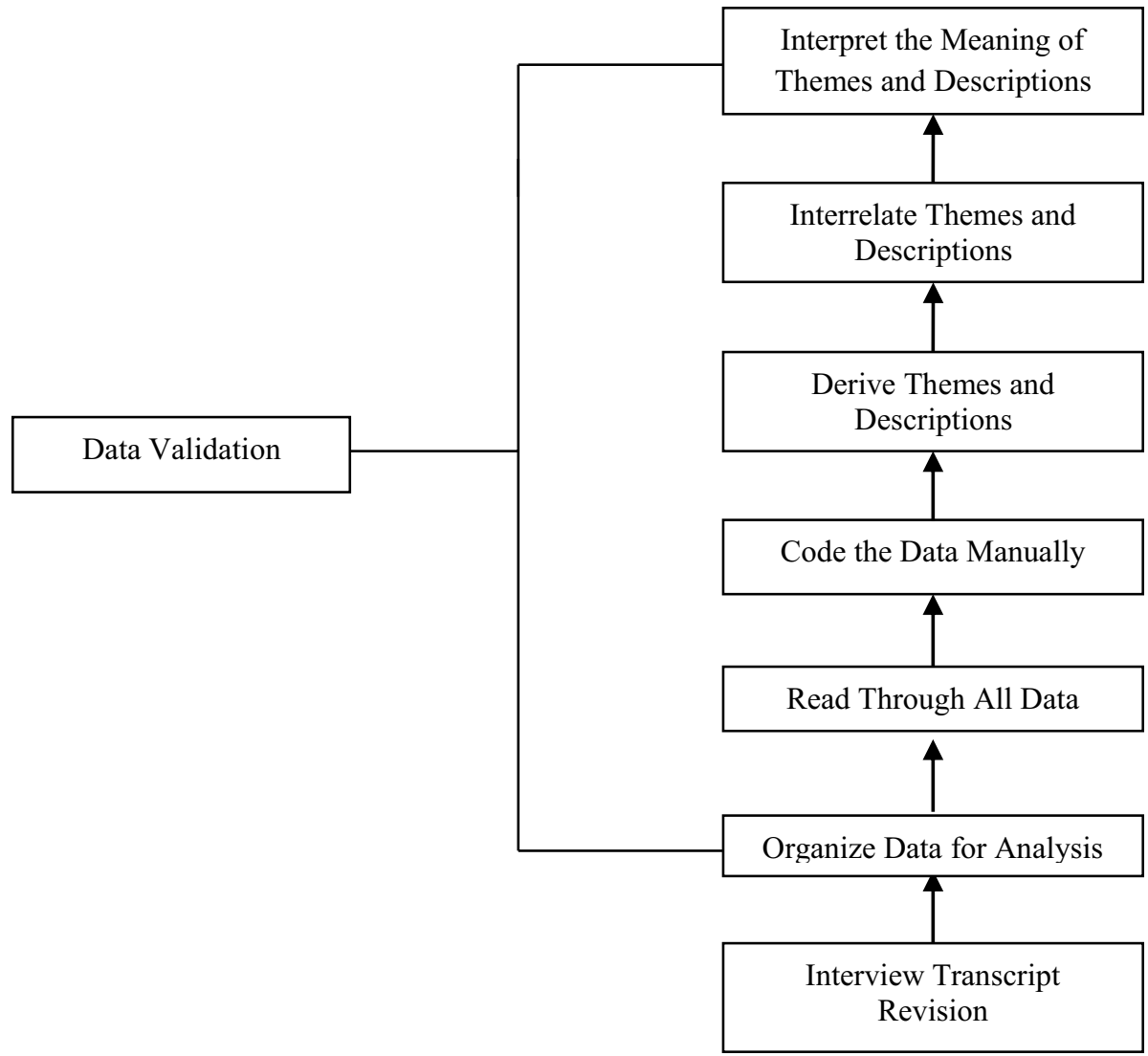

Fig. 2 Qualitative data analysis chart that informs data analysis for this study. In Research design: Qualitative, quantitative, and mixed methods approaches (p. 185), by J. W. Creswell, 2009, (3rd ed.), Thousand Oaks, CA: Sage. Copyright 2009 by Sage 


\subsection{Findings}

This section reports the findings of the qualitative data analysis for the 14 interviews that were conducted at the midsized higher education institution in Qatar. To answer the research questions, the corresponding participants were asked to respond to a series of 10 interview questions that aimed at providing a deeper understanding of the factors that facilitate the integration of technology into instruction (see Appendix 1). Next, representative quotes are presented in the form of narrative passages to show faculty perceptions of the explored phenomenon.

\subsection{External Variables}

The first component of Davis's (1986) TAM is external variables. In effect, external variables are the factors that are either within or beyond faculty members' control, or inside or outside their organizational context. Findings derived from the first component of TAM show that mandating technology-based teaching and providing Arabic enabled software applications and content facilitate technology integration into instruction. More importantly, faculty members viewed cultural restrictions among the external factors facilitating their use of technology for teaching and learning.

\subsubsection{Mandating Technology-Based Teaching}

Five of the participants stressed the importance of mandating a teaching methodology that emphasizes technology use in classroom instruction. Specifically, they argued that university administrators should consider technology integration as a major requirement for faculty tenure and promotion. To explain this point further, Adam shared, "I am sure that faculty will use more technology if it was a top down decision or if it had anything to do with their promotion." Ziad reiterated, "Our leadership should be stricter about educational technology if they want to see it applied inside the classroom." The participants also recommended best practices for using technology in the classroom. Michael stated, "[The] teaching methodology matters. In my class, I use technology for a specific purpose and I do not crisscross objectives. If I am using technology only to evaluate students then students will not attain its educational benefits." Omar concurred, "Aligning specific technology resources with learning objectives is essential for successful technology integration practices. This is essentially important if faculty members are to show their students how theories apply in reality."

\subsubsection{Digital Content Availability is a Prerequisite}

Four of the participants indicated that providing faculty members with Arabic enabled software applications and content facilitates technology integration into instruction. According to them, the availability of online Arabic databases and applications leads to more technology use inside the classroom. Speaking about the importance of digital content, Abdulla shared: 
As you know, Arabic is the language of instruction at this college and a great number of faculty members earned their doctoral degrees from Arab universities. As such, adopting Arabic enabled software applications would make it easier for faculty to use technology for instructional purposes.

Similarly, Ahmad asserted:

Arabic books are outdated and digital content is insufficient for providing our students with the latest information regarding any topic. . . . If universities design Arabic software programs for teaching purposes and provide unlimited access to the available Arabic digital libraries, faculty members will then integrate those resources into their teaching practices.

\subsubsection{Cultural Restrictions Promote Technology Integration}

Eight participants reported cultural restrictions as an external factor that facilitates technology integration into instruction. While research indicates the opposite (e.g., Al-Jaber \& Dutta, 2008; AlMannai, 2017; Bahgat, 1999; Weber, 2010; Wiseman \& Anderson, 2012), the participants assured that cultural restrictions enhance technology use during instruction. More specifically, cultural restrictions helped professors address sensitive topics indirectly by using digital media. Chris clarified this point further:

In Qatar, certain educational objectives are case-sensitive and cannot be covered or discussed inside the class without the support of educational technology. For example, faculty members emphasize documentary videos in their classrooms just to avoid interacting with their students on religious and cultural topics. I had my students today watch a YouTube video on the contradictions between Arab and Western cultures. .. . This helped me show students how others think without engaging in any sort of arguments.

Rafik also noted:

In order to avoid arguments and misunderstandings when talking about issues that sometimes negate religion or culture, I ask students to go over the internet and search for it. Some pick up videos and come to class prepared to discuss and others comment on what people on social media are saying about it.

\subsection{Perceived Usefulness}

The second component of Davis's (1986) TAM is perceived usefulness. Research on technology integration suggests that faculty members are less likely to integrate technology into their instruction if they were not convinced that using it entails job benefits, improves their performance, and enhances student learning (Rogers, 2000a, 2000b; Spotts, 1999). Findings derived from the second component of TAM include time management and career enhancement.

\subsubsection{Technology Saves Time and Improves Productivity}

Eight of the participants reported time management as one of the professional benefits that technology integration into instruction entails. All eight participants explained that 
technology enhances their productivity by enabling them to dedicate their time and energy to teaching, research, and service. Speaking about the relationship between technology and time, Michael, "Technology saves a lot of time and energy, especially when it comes to lesson planning and preparation.... Technology helps me to manage my work efficiently." Similarly, Faisal asserted:

Technology allows me to invest my time on certain [activities] that students and I consider important.... These activities ease student workload, engage students by making learning more interactive, and give us the option to finish our work remotely.... My time is consumed wisely now, so I have more time to engage in other types of institutional and communal activities.

\subsubsection{Technology Supports Career Development}

All of the participants reported career enhancement as a major professional benefit that technology integration into instruction entails. Of note is that all participants concluded that technology integration into instruction is a twenty-first century employability requirement. Specifically, integrating technology into instruction entails a number of professional benefits that include (a) promotion, (b) exposure, and (c) professional development. According to the participants, these professional benefits lead to job security and career enhancement. Commenting further on the professional benefits of technology integration, Majed noted:

Instructional technology is inevitable today. Instructors who do not use technology effectively are simply going to be antiquated and ineffective. They cannot remain competitive if they do not learn how to apply it inside their classrooms. It is the $21 \mathrm{st}$ century employability requirement.

Equally important, Mounir stated, “Technology improves my performance and enhances my career. Also, [technology] helps me deliver information, inform students about the latest technological advancements, and show my colleagues how it can be applied in a classroom setting." Maher also shared, "Technology provides us with job and exposure opportunities by attending webinars and e-conferences. In higher education, it is all about being known in your field."

\subsection{Perceived Ease of Use}

The third component of Davis's (1986) TAM is perceived ease of use. Research indicates that a system that is perceived to be easier to use is more likely to be applied in an organizational context (Davis, 1989). Findings derived from the third component of TAM suggest that technology integration (a) needs basic technology skills, (b) necessitates practice, and (c) requires support.

\subsubsection{Technology Skills are Mandatory}

Nine of the participants perceived basic technology skills as a requirement for successful technology integration practices inside the classroom. With regard to technology literacy, nine participants suggested that faculty members should have prior computer 
experience and basic technology skills to be able to integrate technology into their instruction. Recognizing the importance of possessing basic technology skills, Adam shared:

I believe that basic knowledge of computers is enough. We need not to engage in programming to integrate technology into instruction. . . . The entire technology integration process is simple because software applications are straight forward and require minimal effort.

Similar to Adam, Ziad explained:

Integrating any type of software or hardware into teaching and learning is an easy task because technology is nowadays user-friendly. In Qatar, faculty members need to have basic technology proficiency in order to hit the ground running on the required level.

\subsubsection{Practice Makes Perfect}

Five of the participants stressed the importance of practice in terms of enhancing faculty technology skills and facilitating technology use during instruction. The participants explained that continual practice teaches faculty how to integrate technology into their instruction and introduces instructors to software applications and hardware relevant to their area of expertise. Speaking about the importance of practice, Omar pointed out, "In order to learn how to implement technology in their classrooms, faculty need to embrace trial and error type of learning. Without exploration, there is no learning." Similarly, Salam reported, "My core principle is to try computer technologies prior to applying them in my classroom to avoid troubleshooting during the session."

\subsubsection{Technology Integration is Incremental}

Five of the participants stressed the importance of breaking up the technology integration process into a set of simple tasks. According to them, faculty members view technology integration as an overwhelming process that is time-consuming and difficult to achieve. They believe technology integration should be gradual until mastering how to use specific equipment and applications in their teaching. Amr explained, "Dividing the process of using technology in our teaching into steps would save time and make the entire thing easier for us."

\subsection{Attitude}

Attitude refers to "the degree of evaluative affect that an individual associates with using the target system in his or her job" (Davis, 1986, p. 25). According to TAM, a potential user's attitude toward implementing a given system is assumed to be a major determinant of whether he or she actually uses it. In addition to the perceived benefits of technology, study participants argued that faculty willingness and confidence to use technology create positive attitudes toward its integration. 


\subsubsection{Benefits Command Attitudes}

According to four participants, believing in the benefits of technology predetermines attitudes toward integrating it into instruction. They argued that faculty attitudes toward technology improve as they envision its benefits. According to Rafik:

[Faculty] need to believe that technology helps us achieve our goals in order to change our attitude towards it. I think faculty members will be more passionate about technology if they knew the benefits. . . . If faculty believe that the advantages of technology outnumber the disadvantages, technology will be then integrated into curricula and applied into all university's classrooms.

\subsubsection{Willingness is Indispensable}

According to eleven participants, faculty members' willingness to overcome technophobia and stay current with the latest technologies determines whether they will integrate technology into their instruction. Recognizing the importance of willingness, Amr stated, "I think more faculty fail to integrate technology because they lack willingness or fear of their own abilities." Likewise, Michael shared, "Faculty willingness is essentially vital if they are to overcome their fears of technology and successfully integrate technology into all aspects of their work." Majed further explained, "Instructors who are willing to stay current with the latest technologies will always be able to use technology during instruction."

\subsubsection{Confidence Brings Success}

Six of the participants concluded that self-confidence enhances technology use in classroom instruction. They explained that self-confidence creates a positive attitude that motivates faculty members to integrate technology into their instruction. According to Mounir, "Successful technology integration efforts strictly depend on the extent to which faculty members believe in their skills.... Faculty members who are confident of their skills will always be motivated to perform any task." Chris reiterated, "Faculty who are confident in using technology will go above and beyond to do the job."

\section{Discussion}

Faculty members reported a plethora of factors they believe could facilitate their use of technology inside the classroom. Overall, integrating technology into instruction was perceived as an intricate process that is influenced by multiple factors internal or external to the faculty. These factors resonate with Davis's (1986) TAM and the literature available on technology integration in higher education (Karkouti, 2016). Table 3 categorizes these factors and aligns them with each of TAM's components.

Consistent with the aforementioned findings on the factors that facilitate technology integration into instruction, Okojie et al. (2006) argue that technology-based learning happens when faculty consider technology before "developing learning objectives, methods of instruction, feedback, and evaluation and assessment strategies including follow-up activities" (p. 66). In other words, considering technology as a forethought activity allows faculty to align specific technological tools with student learning preferences, lesson objectives, and learning outcomes. Nevertheless, according to study participants, applying a 
Table 3 Internal and external factors in relation with Davis's (1986) TAM

\begin{tabular}{llll}
\hline TAM Components & Factors & Internal & External \\
\hline External variables & & & \\
& Mandating technology-based teaching & - & $\mathrm{X}$ \\
& Digital content availability & X & $\mathrm{X}$ \\
Cultural restrictions & & - & - \\
Perceived usefulness & Productivity enhancement & $\mathrm{X}$ & - \\
& Career development & $\mathrm{X}$ & - \\
Perceived ease of use & & & - \\
& Basic proficiency & $\mathrm{X}$ & $\mathrm{X}$ \\
& Learning through practice & $\mathrm{X}$ & - \\
Attitude & Incremental adoption & & - \\
& & $\mathrm{X}$ & - \\
\hline
\end{tabular}

A dash indicates an absent value

teaching methodology that aligns technology with learning objectives during the process of instructional design necessitates mandating technology use inside the classroom, enhancing faculty members' English literacy skills, and providing them with Arabic enabled software applications and content. These recommendations require just-in-time technical and institutional support because they are external to faculty members.

One of the major challenges preventing technology integration is lack of digital Arabic content. Given that Arabic is Qatar's official teaching language (Mustafawi \& Shaaban, 2019), a great number of Arab faculty members have limited English skills because they earned their degrees from universities where Arabic is the main language of instruction. This limited English proficiency proved to be problematic due to lack of Arabic enabled software applications and hardware. According to Ibrahim et al. (2020), Arab faculty who lack foreign language skills do not benefit from latest research developments and online technologies because English is the dominant language. In Qatar, language barriers prevent students and their instructors from using online resources because electronic publishing is not common in Arabic (Ibrahim et al., 2020; Karkouti, 2016). In order to overcome this barrier and facilitate technology integration, university administrators should provide faculty with unlimited access to existing online Arabic databases, offer language learning workshops, and develop Arabic enabled software applications and content. Mandating technology was also perceived to facilitate its integration into teaching and learning; however, research suggests the opposite (Yeung et al., 2011). Yeung et al. posit, "Mandating use of [digital technology] may not be useful. A more productive approach may be to enhance the competence of teachers in digital technology so that they value its effectiveness and are confident to apply it in classroom activities" (p. 859).

Relevant to any discussion of educational technology is the effects of culture on its application. Although research indicates the opposite (e.g., Al-Jaber \& Dutta, 2008; Bahgat, 1999; Hiasat, 2018; Weber, 2010; Wiseman \& Anderson, 2012), the majority of participants assured that cultural restrictions enhance technology use during instruction. They 
explained that they rely on digital media to avoid discussing sensitive topics inside the classroom. For example, to avoid engaging in heated arguments, faculty displayed content from social media channels that address restricted topics and ideologies without even showing whether they are for or against it. This finding contradicts Wiseman and Anderson's (2012) argument that ICT is not effectively utilized in knowledge development due to restrictions imposed by cultural norms in Arab Gulf states (Wiseman \& Anderson, 2012). For example, in Qatar, the issue of inappropriate content thwarts the implementation of technology where teachers prevent their children from using the Internet and refuse to enroll them in e-learning programs due to parental anxieties (AlMannai, 2017).

The use of technology in teaching and learning also entails a number of professional benefits that include (a) promotion, (b) exposure, and (c) professional development. This finding is consistent with the available literature on the factors that facilitate technology integration. Mounting evidence suggests that faculty members are less likely to integrate technology into their instruction if they are not convinced that technology usage entails job benefits (i.e., tenure and promotion), and improves their teaching, performance, and overall productivity (Al Meajel \& Sharadgah, 2018; D. L. Rogers, 2000a, 2000b; Shams Eldin, 2020; Spotts, 1999). However, technology integration requires some level of technical skill competency.

Regarding the skills needed to facilitate technology integration into instruction, nine of the participants perceived software applications and hardware as user-friendly devices that can be integrated into instruction with minimal effort. Study participants recommended practicing multiple applications before using them inside the classroom to avoid troubleshooting errors during the session. Exploring available technologies and embracing trialand-error learning could improve faculty technology skills and prepare them to use technology effectively and efficiently while teaching. Equally important, the availability of user-friendly interfaces prompted the participants to conclude that technology use inside the classroom requires basic technology skills. However, Adams (2002), Dempsey et al. (2008), and Georgina and Olson (2007) found that faculty members possessing advanced technology skills are the ones to integrate technology into their instruction. Grisham and Wolsey (2012) noted that teacher candidates, all post-graduates and most of whom were between the ages of 21 and 32, were fearful of using new technology. They believed they needed to be more proficient than the students they would ultimately teach. These seemingly contradictory findings suggest the possibility of a matrix of technology proficiency on one axis and belief in the efficacy of technology on the other. Similarly, studies conducted in Saudi Arabia, a culturally similar context to Qatar on the acceptance and use of technology, found that both faculty members and students have to be technologicallyproficient in order to benefit from educational technology (Al Meajel \& Sharadgah, 2018; Shams Eldin, 2020).

Another significant factor affecting educational technology is the time required to integrate it into instruction. Specifically, study participants explained that technology integration is a complicated process which is negatively perceived by many faculty members who barely have time to focus on teaching, research, and service. Hence, lack of time prevents faculty from using technology efficiently because it adds duties to their already-heavy workload. They recommended providing faculty ample time and easing the integration process by breaking it up into a set of simple tasks. This supports Al Meajel and Sharadgah's (2018) work on the barriers that obstruct the use of online technology systems in teaching and learning. The researchers found that using technology cannot happen without providing faculty enough time, detailed guidelines, and adequate support when developing instruction using online learning platforms. 
Consistent with TAM's (Davis, 1986) explication of attitudes, envisioning the educational benefits of technology creates a favorable attitude towards its integration. According to Fishbein and Ajzen (1975), an individual's attitude toward performing a specific task is best described as one's "positive or negative feelings about performing the target behavior" (p. 216). Study participants explained that faculty beliefs about the benefits of technology create positive attitudes toward its integration, empower faculty to respond to change, and influence their willingness to take responsibilities, overcome technophobia, and stay current with latest technologies. These findings echo other assertions regarding the effects of one's attitudes toward technology use (Abouchedid \& Eid, 2003; Kim et al., 2013; Tabata \& Johnsrud, 2008). For example, Rogers (2000a, 2000b) explained that attitudes toward technology and its uses in education play a pivotal role in determining whether faculty members will utilize it in their instruction. In a study that examined the effects of faculty attitudes on the integration of technology into instruction, Abouchedid and Eid (2004) found that the perceived disadvantages of e-learning and technology intimidation degrade faculty positive attitudes toward educational technology. On the contrary, Kim et al. (2013) and Tabata and Johnsrud (2008) found that the perceived benefits of educational technology significantly enhance its integration into instruction.

In a related vein, study participants reported that faculty confidence of their technology skills positively affects attitudes toward technology use in classroom instruction. According to Valdez et al. (2000), the success or failure of technology integration initiatives rely more on "human and contextual factors than on hardware or software" (p. 4). Given this disposition, one can conclude that self-confidence determines attitudes toward educational technology. This finding corresponds to the literature related to successful technology integration practices in higher education (Al Meajel \& Sharadgah, 2018). Today, higher education institutions view technology integration as intentional classroom practices that support instruction, promote learning of content, and demonstrate mastery of that content using educational technology (Al Meajel \& Sharadgah, 2018; Cradler et al., 2002; Javeri \& Persichette, 2007; Okojie et al., 2006).

Finally, findings from this study show that successful technology integration practices are the product of multiple factors, internal or external to the faculty. As TAM's four interrelated constructs (i.e., external variables, perceived usefulness, perceived ease of use, and attitude) combine, they form a person's behavioral intention, and intentions are predictive of whether a person will use any computer-based technology or system (Davis, 1986). Behavioral intention is defined as "a measure of the strength of one's willingness to perform a specific behavior" (Davis et al., 1989, p. 984). TAM posits that behavioral intention is formed because of a conscious decision-making process which means that faculty have to commit to change in order to successfully integrate technology into their instruction (Venkatesh et al., 2003). This explains why internal factors have outnumbered external ones in this study.

\subsection{Limitations and Future Research}

As with any investigation, this qualitative, exploratory case study has multiple limitations. In addition to the relatively low number of participants $(N=14)$, purposive sampling, and engaging at a single higher education setting, the study population only included male faculty members holding doctoral degrees (i.e., full-time assistant and associate professors). This limitation indicates the findings might not apply to female professors and other instructors who hold masters and bachelor degrees. In order to validate the results of this 
study, future investigations should employ qualitative and quantitative research methods, recruit participants of both genders, and engage multiple higher education institutions in Qatar. Other researchers, using the same theoretical framework and multiple data collection tools, could replicate this study at public and private higher education institutions in order to gather additional perspectives from samples with different ranks and demographic variables.

A longitudinal investigation on faculty beliefs and changes in beliefs over time as well as changes in technology integration practices is also warranted. One of the significant findings of this study was that faculty members perceived beliefs of the value of educational technology as a major determinant of successful technology integration practices. Therefore, a longitudinal study that compares beliefs against technology integration practices over time would provide a better explanation of belief dynamics in terms of technology integration. In addition to multi-time measurements, researchers have to consider a multi-method approach to validate the results of their investigations.

Finally, cultural restrictions were perceived among the factors that facilitate technology integration into instruction. Therefore, a study that examines the impact of cultural restrictions on technology use would enrich the existing knowledge base and provide Qatari policymakers and educational leaders in similar culturally restrictive environments with worthwhile data on the factors that enhance the use of technology inside the classroom.

\section{Conclusion and Implications}

Technology integration into instruction requires a complex interplay of factors, internal and external to the adopter. The present study demonstrates this complexity in several ways that can be instructive for higher education policymakers and those charged with faculty development. Notably, professors in this study focused heavily in their responses to the technology itself and less on the pedagogical uses of the tools. Further, they often spoke of factors that are not directly related to instruction. By conflating technology integration for instruction with other aspects of being a professor, such as tenure and promotion and productivity, participants signal that they may view all aspects of the job as interrelated. However, on balance, they also tend to agree that a mandate for technology will help to persuade those less ready for technology integration and an incremental approach to adoption are necessary.

Higher education leadership may employ the findings of this study in several ways. Leveraging external factors may lead to greater behavioral intention on the part of faculty who are less likely to integrate technology successfully. External factors that include mandates for technology integration would do well to consider the incremental approach recommended by many of the professors in this study. This may mean a stepwise plan for integration by business units (e.g., schools, departments, centers) while also taking a stepwise approach for individual faculty members. Similarly, a plan for technology integration should attend to internal factors that professors value while emphasizing intersections of content and discipline with appropriate pedagogies that may be effectively implemented in the classroom (see Koehler \& Mishra, 2008). The implications of the present study correlate with others (Scherer et al., 2021) that indicate long-term plans for technology integration at the institutional and governmental levels are likely to increase the probability that the professoriate will come to see the value of integration. For the professors in this 
study, institutional and governmental support should certainly include attention to developing interfaces and content that are Arabic-friendly.

Today, Qatar, is in the midst of an ambitious national development plan that aims at establishing the country as a fully-developed nation "Qatar National Vision 2030." Therefore, in order to realize Qatar's national vision, policymakers and educational leaders are required to generate context specific policies that propel the paradigm shift from teaching to learning. This paradigm shift requires significant changes including faculty members' envisioning the benefits of educational technology, postsecondary institutions' reconfiguring education to take full advantage of the emerging technologies, educational leaders' providing faculty members with needed types of support, and instructional technologists' developing cohesive training programs that move beyond teaching basic technology skills to include teaching faculty how to align specific technological resources with course content and methods of instruction.

\section{Appendix 1: Interview Questions}

1. What are the external factors that positively influence and enhance the integration of technology into your instruction?

Note: External factors represent the factors that are either within or beyond faculty members' control, inside or outside their organizational context.

2. What is your understanding of the educational benefits of integrating technology into instruction?

3. As a faculty member, what are the professional benefits that technology integration into instruction entails?

4. To what extent do you believe that educational technology systems are user-friendly?

5. What are your perceptions regarding the expertise or skills needed to facilitate the integration of technology into instruction?

6. In your experience, what are the most effective strategies that alter negative perceptions on technology integration into instruction?

7. In your experience, what attitudes promote technology integration into instruction?

8. In your experience, what are the factors that motivate faculty members to integrate technology into their instruction?

9. How do you perceive professional rewards in terms of motivating faculty members to integrate technology into their instruction?

10. What additional insights would you like to share regarding integrating technology into your instruction?

Acknowledgements Ibrahim M. Karkouti is an Assistant Professor of Educational Leadership at the Graduate School of Education, the American University in Cairo. Dr. Karkouti's research focuses on the elements that aid in the facilitation of the use of technology inside the classroom and the types of social support refugee students need to excel at school. 


\section{References}

Abouchedid, K., \& Eid, G. M. (2004). E-learning challenges in the Arab world: Revelations from a case study profile. Quality Assurance in Education, 12(1), 15-27. https://doi.org/10.1108/0968488041 0517405

Abu Samak, Z. T. (2010). Information and communication technology integration among Jordanian English language teachers. In I. Ismail (Ed.), Proceedings of the 5th International Conference on e-Learning (pp. 11-18). Academic Press.

Adams, N. B. (2002). Educational computing concerns of postsecondary faculty. Journal of Research on Technology in Education, 34(3), 285-303. https://doi.org/10.1080/15391523.2002.10782350

Al-Jaber, H., \& Dutta, S. (2008). Qatar: Leveraging technology to create a knowledge-based economy in the Middle East. World Economic Forum.

Alkhateeb, B. (2019). Educational technology self-efficacy beliefs of student teachers at Qatar University and its relation to their program preparedness for technology integration [Unpublished master's thesis]. Qatar University.

AlMannai, K. A. (2017). Teachers' perceptions of one-to-one computing effect on learning environment in Qatari secondary schools [Unpublished master's thesis]. Qatar University.

Al Meajel, T. M., \& Sharadgah, T. A. (2018). Barriers to using the Blackboard system in teaching and learning: Faculty perceptions. Technology, Knowledge and Learning, 23, 351-366. https://doi.org/ 10.1007/s10758-017-9323-2

Al-Senaidi, S., Lin, L., \& Poirot, J. (2009). Barriers to adopting technology for teaching and learning in Oman. Computers and Education, 53(3), 575-590. https://doi.org/10.1016/j.compedu.2009.03.15

Anderson, B., \& Horn, R. (2012). Community colleges in the information age: Gains associated with students' use of computer technology. Journal of Educational Computing Research, 47(1), 51-65. https://doi.org/10.2190/EC.47.1.c

Anthony, B., Jr., Kamaludin, A., Romli, A., Raffei, A. F., Eh Phon, D. N., Abdullah, A., \& Ming, G. L. (2020). Blended learning adoption and implementation in higher education: A theoretical and systematic review. Technology, Knowledge and Learning. https://doi.org/10.1007/ s10758-020-09477-z

Badran, A., Baydoun, E., \& Hillman, J. R. (Eds.). (2019). Major challenges facing higher education in the Arab world: Quality assurance and relevance. Springer Publishing Company.

Bahgat, G. (1999). Education in the Gulf monarchies: Retrospect and prospect. International Review of Education, 45(2), 127-136.

Breslin, J., \& Jones, T. (2010). Qatar. In S. Kelly \& J. Breslin (Eds.), Progress amid resistance: Women's rights in the Middle East and North Africa (pp. 397-424). Freedom House.

Brewer, D. J., Augustine, C. H., Zellman, G. L., Ryan, G., Goldman, C. A., Stasz, C., \& Constant, L. (2007). Education for a new era: Design and implementation of K-12 education reform in Qatar. RAND Corporation.

Brill, J. M., \& Galloway, C. (2007). Perils and promises: University instructors' integration of technology in classroom-based instruction. British Journal of Educational Technology, 38(1), 95-105. https://doi. org/10.1111/j.1467-8535.2006.00601.x

Brown, M. G. (2016). Blended instructional practice: A review of the empirical literature on instructors' adoption and use of online tools in face-to-face teaching. Internet and Higher Education, 38, 1-10. https://doi.org/10.1016/j.iheduc.2016.05.001

Bryman, A. (2012). Social research methods (4th ed.). Oxford University.

Camilleri, M. A., \& Camilleri, A. C. (2017). Digital learning resources and ubiquitous technologies in education. Technology, Knowledge and Learning, 22, 65-82. https://doi.org/10.1007/s10758-016-9287-7

Casas, A. C. (2010). Factors that determine attitudes toward the use technology to plan for retirement: An empirical analysis. Paper presented at the Academy of Financial Services 2010 Annual Meeting, Sparkill, NY. Abstract retrieved from https://www.academyfinancial.org/resources/Documents/Proce edings/2010/6B-Casas.pdf

Casey, J. E., Pennington, L. K., \& Mireles, S. V. (2020). Technology acceptance model: Assessing preservice teachers' acceptance of floor-robots as a useful pedagogical tool. Technology, Knowledge and Learning. https://doi.org/10.1007/s10758-020-09452-8

Chaaban, Y., \& Ellili-Cherif, M. (2017). Technology integration in EFL classrooms: A study of Qatari independent schools. Education and Information Technologies, 22, 2433-2454. https://doi.org/10.1007/ s10639-016-9552-3

Cheng, W-L., Dohrmann, T., Kerlin, M., Law, J., \& Ramaswamy, S. (2018). Creating an effective workforce system for the new economy. Retrieved from https://www.mckinsey.com/industries/public-sector/ourinsights/creating-an-effective-workforce-system-for-the-new-economy 
Cradler, J., McNabb, M., Freeman, M., \& Burchett, R. (2002). How does technology influence student learning? Learning \& Leading with Technology, 29(8), 47-56.

Davis, F. D. (1986). A technology acceptance model for empirically testing new end-user information systems: Theory and results (Doctoral dissertation). Retrieved from http://dspace.mit.edu/handle/1721.1/ 15192

Davis, F. D. (1989). Perceived usefulness, perceived ease of use, and user acceptance of information technology. Management Information Systems Quarterly, 13(3), 319-340.

Davis, F. D., Bagozzi, R. P., \& Warshaw, P. R. (1989). User acceptance of computer technology: A comparison of two theoretical models. Management Science, 35(8), 982-1003.

Dempsey, J. V., Fisher, S. F., Wright, D. E., \& Anderton, E. (2008). Training and support, obstacles, and library impacts on elearning activities. College Student Journal, 42(2), 630-636.

Diaz, D. P., \& Bontenbal, K. F. (2000). Pedagogy-based technology training. In P. Hoffman \& D. Lemke (Eds.), Teaching and learning in a network world (pp. 50-54). 105 Press.

Edwyn, J. (2001). Learning to change: ICT in schools. Organization for Economic Cooperation and Development.

Ertmer, P. A. (2005). Teacher pedagogical beliefs: The final frontier in our quest for technology integration? Educational Technology Research and Development, 53(4), 25-39.

Faek, R. (2020). Coronavirus outbreak forces Arab countries to consider long-ignored online education. https://www.al-fanarmedia.org/2020/03/coronavirus-outbreak-forces-arab-countries-to-consider-longignored-online-education/

Fathema, N., Shannon, D., \& Ross, M. (2015). Expanding the technology acceptance model (TAM) to examine faculty use of learning management systems in higher education institutions. Journal of Online Learning and Teaching, 11(2), 210-232.

Faudler, T. R. (2011). Technology integration: A research-based professional development program [Unpublished master's thesis]. Mount Vernon Nazarene University.

Fishbein, M., \& Ajzen, I. (1975). Belief, attitude, intention, and behavior: An introduction to theory and research. Addison-Wesley.

Gay, A. (2019). How digital literacy affects the modern workforce. Retrieved from https://theblog.adobe. com/how-digital-literacy-affects-the-modern-workforce/

Georgina, D. A., \& Olson, M. R. (2007). Integration of technology in higher education: A review of faculty self-perceptions. Internet and Higher Education, 11(1), 1-8. https://doi.org/10.1016/j.ihedue.2007. 11.002

Grisham, D. L., \& Wolsey, T. D. (2012). A constructivist view of podcasting: Teacher candidates create the media. Journal of School Connections, 4(1), 53-80.

Hassad, R. A. (2013). Faculty attitude toward technology-assisted instruction for introductory statistics in the context of educational reform. Technology Innovation in Statistics Education, 7(2), 1-17.

Hecht, J. B. (2001). Future shock: Education in the information age. Mid-Western Educational Researcher, 14(1), 3-12.

Hiasat, L. (2018). Blended and experiential learning for Emiratis in tertiary education. The Journal of Asia TEFL, 15(3), 874-881.

Ibrahim, Q. A., Sorur, M., Labidi, L., \& Osburn, L. G. (2020). Quality of social work education and practice in the Arab countries: A comparative study of Palestine Qatar and Tunisia. Social Work Education. https://doi.org/10.1080/02615479.2020.1773781

Javeri, M., \& Persichitte, K. (2007). Measuring technology integration practices of higher education faculty with an innovation component configuration map (ICCM). International Journal of Technology in Teaching and Learning, 3(1), 28-50.

Jones, S. R., Torres, V., \& Arminio, J. (2014). Negotiating the complexities of qualitative research in higher education: Fundamental elements and issues (2nd ed.). Routledge.

Kaminski, K., \& Bolliger, D. (2012). Technology, learning, and the classroom: Longitudinal evaluation of a faculty development model. Journal of Faculty Development, 26(1), 13-17.

Karkouti, I. M. (2016). University faculty members' perceptions of the factors that facilitate technology integration into their instruction: An exploratory case study in Qatar [Unpublished doctoral dissertation]. University of Hartford.

Keengwe, J. (2007). Faculty integration of technology into instruction and students' perceptions of computer technology to improve student learning. Journal of Information Technology Education, 6, 169-180.

Kim, C., Kim, M. K., Lee, C., Spector, J. M., \& DeMeester, K. (2013). Teacher beliefs and technology integration. Teaching and Teacher Education, 29, 76-85. https://doi.org/10.1016/j.tate.2012.08.005

Kindilchie, A. I., \& Samarraie, I. F. (2008). Interaction and impact of electronic resources on Qatar University faculty. Libri, 58(4), 281-293. 
Koehler, M. J., \& Mishra, P. (2008). Introducing TPACK. In AACTE Committee on Innovation \& Technology (Eds.), Handbook of technological pedagogical content knowledge for educators (pp. 3-29). Routledge

Koruyan, K. (2016). The influence of technology-enhanced task design on the development of language learner autonomy and motivation in an Anatolian high school; A case study [Unpublished Doctoral dissertation]. The Open University.

Kumpulainen, K. (2007). Educational technology: Opportunities and challenges. University of Oulu.

Leggett, W. P., \& Persichitte, K. A. (1998). Blood, sweat, and tears: 50 years of technology implementation obstacles. TechTrends, 43(3), 33-36. https://doi.org/10.1007/BF02824053

Li, Y., Garza, V., Keicher, A., \& Popov, V. (2019). Predicting high school teacher use of technology: Pedagogical beliefs, Technological beliefs and attitudes, and teacher training. Technology, Knowledge and Learning, 24, 501-518. https://doi.org/10.1007/s10758-018-9355-2

Martirosyan, N. M., Kennon, J. L., Saxon, D. P., Edmonson, S. L., \& Skidmore, S. T. (2017). Instructional technology practices in developmental education in Texas. Journal of College Reading and Learning, 47(1), 3-25. https://doi.org/10.1080/10790195.2016.1218806

McLoughlin, J. A., Wang, L.-C.C., \& Beasley, W. A. (2008). Transforming the college through technology: A change of culture. Innovative Higher Education, 33(2), 99-109. https://doi.org/10.1007/ s10755-008-9065-0

Mirza, A. A., \& Al-Abdulkareem, M. (2011). Models of e-learning adopted in the Middle East. Applied Computing and Informatics, 9(2), 83-93. https://doi.org/10.1016/j.aci.2011.05.001

Mustafawi, E., \& Shaaban, K. (2019). Language policies in education in Qatar between 2003 and 2012: From local to global then back to local. Language Policy, 18, 209-242. https://doi.org/10.1007/ s10993-018-9483-5

Nasser, R. (2017). Qatar's educational reform past and future: Challenges in teacher development. Open Review of Educational Research, 4(1), 1-19. https://doi.org/10.1080/23265507.2016.1266693

Okojie, M. C., Olinzock, A. A., \& Okojie-Boulder, T. C. (2006). The pedagogy of technology integration. The Journal of Technology Studies, 32(2), 66-71.

Patton, M. Q. (2002). Qualitative research \& evaluation methods (3rd ed.). Sage Publications.

Porter, W. W., Graham, C. R., Spring, K. A., \& Welch, K. R. (2014). Blended learning in higher education: Institutional adoption and implementation. Computers \& Education, 75, 185-195. https://doi.org/10. 1016/j.compedu.2014.02.011

Reilly, B. (2008). Digital encounters: Using information technology in an overseas branch campus. The History Teacher, 41(4), 531-541.

Rogers, D. L. (2000a). A paradigm shift: Technology integration for higher education in the new millennium. Educational Technology Review, 1(13), 19-33.

Rogers, P. L. (2000b). Barriers to adopting emerging technologies in education. Journal of Educational Computing Research, 22(4), 455-472.

Romanowski, M. H., \& Nasser, R. (2012). Critical thinking and Qatar's education for a new era: Negotiating possibilities. International Journal of Critical Pedagogy, 4(1), 118-134.

Rostron, M. (2009). Liberal arts education in Qatar: Intercultural perspectives. Intercultural Education, 20(3), 219-229. https://doi.org/10.1080/14675980903138517

Turugare, M., \& Rudhumbu, N. (2020). Integrating technology in teaching and learning in universities in Lesotho: Opportunities and challenges. Education and Information Technologies, 25, 3593-3612. https://doi.org/10.1007/s10639-019-10093-3

Sadik, A. (2013). The societal acceptance of online degrees in the Arab world: Evidence from two countries. Paper presented at the Third International Conference for E-Learning and Distance Education, Riyadh, Saudi Arabia.

Safar, A. H., \& Alkhezzi, F. A. (2013). Beyond computer literacy: Technology integration and curriculum transformation. College Student Journal, 47(4), 614-626.

Scherer, R., Howard, S. K., Tondeur, J., \& Siddiq, F. (2021). Profiling teachers' readiness for online teaching and learning in higher education: Who's ready? Computers in Human Behavior, 118, 106675. https:// doi.org/10.1016/j.chb.2020.106675

Schindler, L. A., Burkholder, G. J., Morad, O. A., \& Marsh, C. (2017). Computer-based technology and student engagement: A critical review of the literature. International Journal of Educational Technology in Higher Education, 14(25), 1-28.

Shams Eldin, A. Y. (2020). Faculty members' behaviors towards technology acceptance and its impact on a value-added configuration. International Journal of Academic Research in Business and Social Sciences, 10(3), 221-241. https://doi.org/10.6007/IJARBSS/v10-i3/7041 
Shroff, R. H., Deneen, C. C., \& Ng, E. M. (2011). Analysis of the technology acceptance model in examining students' behavioral intention to use an e-portfolio system. Australasian Journal of Educational Technology, 27(4), 600-618.

Smith, D. G. (2009). Diversity's promise for higher education: Making it work. Johns Hopkins University.

Spotts, T. H. (1999). Discriminating factors in faculty use of instructional technology in higher education. Educational Technology \& Society, 2(4), 92-99.

Stanley, D. (2013). Can technology improve large class learning? The case of an upper-division business core class. Journal of Education for Business, 88(5), 265-270. https://doi.org/10.1080/08832323. 2012.692735

Stasz, C., Eide, E. E., Martorell, F., Constant, L., Goldman, C. A., Moini, J. S., Nadareishvili, V., \& Salem, H. (2007). Post-secondary education in Qatar: Employer demand, student choice, and options for policy. RAND Corporation.

Straub, D., Keil, M., \& Brenner, W. (1997). Testing the technology acceptance model across cultures: A three country study. Information and Management, 33(1), 1-11.

Strauss, A., \& Corbin, J. M. (1990). Basics of qualitative research: Grounded theory procedures and techniques. Sage Publications.

Sturgeon, C. M. (2011). Faculty perceptions of the factors enabling and facilitating their integration of instructional technology in teaching [Unpublished doctoral dissertation]. University of Tennessee.

Surry, D. W., Ensminger, D. C., \& Haab, M. (2005). A model for integrating instructional technology into higher education. British Journal for Educational Technology, 36(2), 327-329. https://doi. org/10.1111/j.1467-8535.2005.00461.x

Tabata, L. N., \& Johnsrud, L. K. (2008). The impact of faculty attitudes toward technology, distance education, and innovation. Research in Higher Education, 49(7), 625-646.

Tang, T. L. P., \& Austin, M. J. (2009). Students' perceptions of teaching technologies, application of technologies, and academic performance. Computers and Education, 53(4), 1241-1255. https:// doi.org/10.1016/j.compedu.2009.06.007

Taylor, S., \& Todd, P. A. (1995). Understanding information technology usage: A test of competing models. Information Systems Research, 6(2), 144-176.

United Nations Development Program. (2001). Human development report 2001: Making technologies work for human development. Author.

United Nations Educational, Scientific and Cultural Organization. (2013). Information and communication technology (ICT) in education in five Arab states: A comparative analysis of ICT integration and e-readiness in schools in Egypt, Jordan, Oman, Palestine, and Qatar. Montreal, Canada: UNESCO Institute for Statistics.

U.S. Department of Education. (1996). Getting America's students ready for the 21st century: Meeting the technology literacy challenge. Author.

U.S. Department of Education. (2017). Reimagining the role of technology in education: 2017 national education technology plan update. Retrieved from https://tech.ed.gov/files/2017/01/NETP17.pdf

Valdez, G., McNabb, M., Foertsch, M., Anderson, M., Hawkes, M., \& Raack, L. (2000). Computerbased technology and learning: Evolving uses and expectations. North Central Regional Educational Laboratory.

Vannatta, R. A., \& Beyerbach, B. (2000). Facilitating a constructivist vision of technology integration among education faculty and preservice teachers. Journal of Research on Computing in Education, 33(2), 132-148.

Venkatesh, V. (2000). Determinants of perceived ease of use: Integrating control, intrinsic motivation, and emotion into the technology acceptance model. Information Systems Research, 11(4), 342-365.

Venkatesh, V., \& Davis, F. D. (2000). A theoretical extension of the technology acceptance model: Four longitudinal field studies. Management Science, 46(2), 186-204.

Venkatesh, V., Morris, M. G., Davis, G. B., \& Davis, F. D. (2003). User acceptance of information technology: Toward a unified view. Management Information Systems Quarterly, 27(3), 425-478.

Weber, A. S. (2010). Web-based learning in Qatar and the GCC states. Center for International and Regional Studies.

Wegner, S. B., Holloway, K. C., \& Garton, E. M. (1999). The effects of Internet-based instruction on student learning. Journal of Asynchronous Learning Networks, 3(2), 98-106.

Wickersham, L. E., \& McElhany, J. A. (2010). Bridging the divide: Reconciling administrator and faculty concerns regarding online education. The Quarterly Review of Distance Education, 11(1), 1-12.

Yilmaz, Y., Lal, S., Tong, X. C., Howard, M., Bal, S., Bayer, I., Monteiro, S., Chan, T., \& M. . (2020). Technology-enhanced faculty development: Future trends and possibilities for health sciences education. Medical Science Education, 30, 1787-1796. https://doi.org/10.1007/s40670-020-01100-1 
Wiseman, A. W., \& Anderson, E. (2012). ICT-integrated education and national innovation systems in the Gulf Cooperation Council (GCC) countries. Computers and Education, 59(2), 607-618. https://doi. org/10.1016/j.compedu.2012.02.006

Wixom, B. H., \& Todd, P. A. (2005). A theoretical integration of user satisfaction and technology acceptance. Information Systems Research, 16(1), 85-102.

Yeung, A. S., Taylor, P. G., Hui, C., Lam-Chiang, A. C., \& Low, E. (2011). Mandatory use of technology in teaching: Who cares and so what? British Journal of Educational Technology, 43(6), 859-870. https://doi.org/10.1111/j.1467-8535.2011.01253.x

Yin, R. K. (2014). Case study research: Design and methods (5th ed.). Sage Publications.

Yuen, A. H., \& Ma, W. W. (2002). Gender differences in teacher computer acceptance. Journal of Technology and Teacher Education, 10(3), 365-382.

Publisher's Note Springer Nature remains neutral with regard to jurisdictional claims in published maps and institutional affiliations. 